Even though it can be expressed in very simple terms, this is a very sophisticated piece of mathematics. Jones' discovery was generated by finding a different point of view on a piece of work he had done on a seemingly unrelated problem.

One conceptual problem raised by Jones' work is that although knot theory is intrinsically three-dimensional, after all a knot is a curve in three-dimensional space, his technique is to draw a twodimensional picture and then to read off the invariant. Of course this does not affect the usefulness nor the importance of his work. The problem of finding a conceptual three-dimensional interpretation was solved by Edward Witten using techniques from quantum field theory, an area of physics which is seemingly quite unrelated to knot theory.

Atiyah concentrates on explaining some of the geometrical ideas behind Witten's approach to the Jones poly-

\section{Homo turmoil}

\section{Michael Day}

The Evolution of Homo erectus. By G. Philip Rightmire. Cambridge University Press: 1990. Pp. 260. £32.50, \$44.50.

OF the three stages we know of the evolution of man (the australopithecine apemen, Homo erectus the first true men, and early Homo sapiens our own species) Homo erectus of the Middle Pleistocene would have seemed the most clearly understood and the most taxonomically stable of them all a relatively few years ago - not any more. Important new finds as well as new ways of thinking about hominid taxonomy have thrown this 'species' into the same turmoil as all of the others.

The first find that was attributed to this taxon was that of Java Man, found at the turn of the century by the Dutchman Eugene Dubois: this was followed by the finds of Peking Man in China by Davidson Black in the 1920 s and the further finds of the great Ralph von Koenigswald in the 1930 s and 1940s. This group of material formed the basis for Louis Leakey's theory that man arose as an Asian species rather than one from Africa. The 1960s found Louis Leakey ahead in this debate when his recovery of a Homo erectus calvaria from Bed II at Olduvai and of Homo habilis from the Lower Pleistocene deposits of Bed I in Olduvai Gorge seemed to shift the cradle of humanity firmly to Africa. The discoveries of Richard Leakey from the region of Lake Turkana, north Kenya, of both australopithecines and hominines in the 1970 s and 1980 s added to this view of human origins. This phase of discovery was crowned by the find of the 'Turkana Boy', a young nomials and how this fits in with other aspects of Witten's most recent work in quantum field theory and its relationship with geometry and topology. The exposition is admirably lucid and elegant and I cannot imagine a better introduction, for graduate students and the more experienced, for mathematicians and physicists, to the large amount of high-powered mathematics required. The book is an expanded version of a series of lectures, and, as in his lectures, Atiyah achieves such a degree of clarity by emphasizing ideas and motivation rather than details - the reader who would like to see a detailed account will have to look elsewhere but will be well prepared to appreciate the more technical aspects of the theory. As a source of insight this book is marvellous.

John D. S. Jones is in the Mathematics Institute, The University of Warwick, Coventry CV4 7AL, UK.

skeleton that is attributed to Homo erectus and is almost complete and believed to be 1.6 million years old.

Europe and north Africa have also seen the discovery of new material - such as that from Bilzingsleben in Germany and Petralona in Greece - to add to the wellknown Mauer jaw and Ternifine remains and attributed by some to Homo erectus.

In short, what was a relatively clear picture of Middle Pleistocene hominine evolution has become turbid and debate has centred around all of the following questions. Does Homo erectus exist as a true species or should it be sunk into Homo sapiens? Is it a palaeospecies that exists in true form as a segment of the line that emerges from Homo habilis and gave rise to Homo sapiens? Is Homo erectus an extinct form that had no part to play in the evolution of Homo sapiens? Is there a good example of Homo erectus in the European fossil record? Finally, are the Asian forms of Homo erectus so far removed from the evolution of Homo sapiens in Africa to cast doubt on the existence of Homo erectus in Africa at all? The Evolution of Homo erectus is the personal testimony of Philip Rightmire, and some of these questions, but not all, are answered by him on the basis of comparative anatomical studies that have extended over many years and the examination of almost all of the original material.

On this basis there is no doubt whatsoever that the work is authoritative and contains extended anatomical descriptions of the skulls and jaws: the postcranial remains and teeth, perhaps mercifully, command less detailed attention. It finally becomes clear that Rightmire believes that Homo erectus is indeed a species "spread from Africa to Asia by the onset of the Middle Pleistocene" and again "Homo erectus is a real palaeospecies rather than an arbitrary grade or stage in the evolution of a lineage". The question of the existence of this taxon in Europe is left open but the direct but gradual transformation of Homo erectus into Homo sapiens is not supported from this review of the evidence.

The style of writing is in keeping with the man, calm, assured and competent, but the text is a little dull. On the other hand, the best operative surgeon that I ever watched was the dullest - nothing ever went wrong and there was no drama. The Evolution of Homo erectus is not a textbook for undergraduate students, not a monograph or a handbook, but a useful volume on a topical debate that professionals will consult frequently.

Michael Day is in the Department of Palaeontology, The Natural History Museum, Cromwell Road, London SW7 5BD, UK.

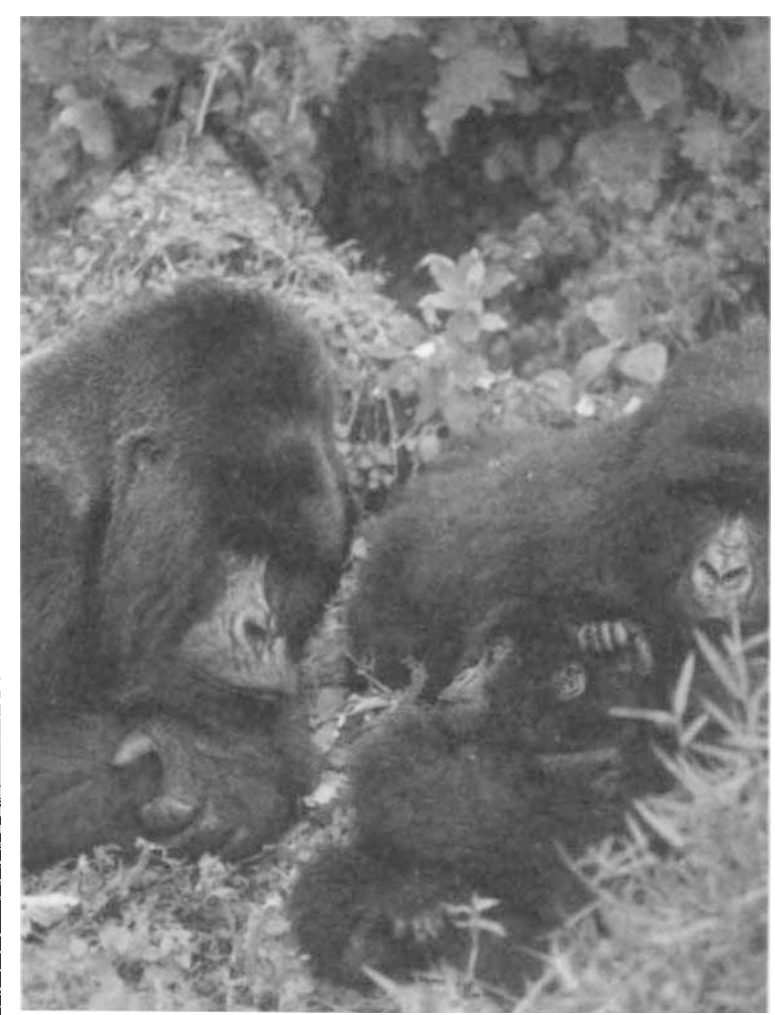

Fatherly love? - An adult male gorilla (left) looks closely at one of his offspring, seeming the image of the doting father. The Mountain Gorilla by Boyd Norton is a delightful portrayal of these animals and the myths that surround them. Published by Swan Hill Press, price is $£ 16.95$. 